九州大学学術情報リポジトリ

Kyushu University Institutional Repository

\title{
Proton conduction properties of hydrous sulfated nano-titania synthesized by hydrolysis of titanyl sulfate
}

Sakai, Takaaki

Environmental Technology Research Division, INAMORI Frontier Research Center, Kyushu University

Kajitani, Satoshi

Department of Applied Chemistry, Faculty of Engineering, Kyushu University

Kim, Seok-Jun

Department of Automotive Science, Graduate School of Integrated Frontier Sciences, Kyushu University

Hamagami, Jun-ichi

Department of Materials Science and Engineering, Kurume National College of Technology

他

http://hdl. handle. net/2324/25996

出版情報：Solid State Ionics. 181 (39/40)，pp.1746-1749，2010-12-20. Elsevier バージョン：

権利関係: (C) 2010 Elsevier B.V. 
Proton conduction properties of hydrous sulfated nano-titania synthesized by hydrolysis of titanyl sulfate

Takaaki Sakai $^{\mathrm{a}^{*} \text {, Satoshi Kajitani }}{ }^{\mathrm{b}}$, Seok-Jun Kim ${ }^{\mathrm{c}}$, Jun-ichi Hamagami ${ }^{\mathrm{d}}$, Hiroyuki Oda ${ }^{\mathrm{e}}$, Maki Matsuka ${ }^{\mathrm{b}, \mathrm{f}}$, Hiroshige Matsumoto ${ }^{\mathrm{a}^{*}}$ and Tatsumi Ishihara ${ }^{\mathrm{b}, \mathrm{c}}$

${ }^{a}$ Environmental Technology Research Division, INAMORI Frontier Research Center, Kyushu University, 744 Motooka, Nishi-ku, Fukuoka 819-0395, Japan

${ }^{b}$ Department of Applied Chemistry, Faculty of Engineering, Kyushu University, 744 Motooka, Nishi-ku, Fukuoka 819-0395, Japan

${ }^{c}$ Department of Automotive Science, Graduate School of Integrated Frontier Sciences, Kyushu University, 744 Motooka, Nishi-ku, Fukuoka 819-0395, Japan

${ }^{\mathrm{d}}$ Department of Materials Science and Engineering, Kurume National College of Technology, 1-1-1 Komorino, Kurume, Fukuoka, 830-8555, Japan

e Department of Environmental and Life Sciences, Toyohashi University of Technology, 1-1 Hibarigaoka, Tempaku-cho, Toyohashi, Aichi 441-8580, Japan

${ }^{\mathrm{f} I n t e r n a t i o n a l ~ E d u c a t i o n ~ C e n t e r, ~ F a c u l t y ~ o f ~ E n g i n e e r i n g, ~ K y u s h u ~ U n i v e r s i t y, ~} 744$ Motooka, Nishi-ku, Fukuoka 819-0395, Japan 
*Corresponding author: Dr. Takaaki Sakai

Environmental Technology Research Division, INAMORI Frontier Research Center, Kyushu University, 744 Motooka, Nishi-ku, Fukuoka 819-0395, Japan

Tel: +81-92-802-6965, Fax: +81-92-802-6965

E-mail: sakai@ifrc.kyushu-u.ac.jp

*Corresponding author: Dr. Hiroshige Matsumoto

Environmental Technology Research Division, INAMORI Frontier Research Center, Kyushu University, 744 Motooka, Nishi-ku, Fukuoka 819-0395, Japan

Tel: +81-92-802-6964, Fax: +81-92-802-6964

E-mail: matsumoto@ifrc.kyushu-u.ac.jp 


\begin{abstract}
We investigated the electrical conductivity and electrochemical properties of hydrous sulfated nano-titania. The conductivity reached $0.1 \mathrm{~S} \mathrm{~cm}^{-1}$ at $50^{\circ} \mathrm{C}$ under relative humidity of $80 \%$. Diffuse reflectance FT-IR spectra suggest that bidentate sulfate coordination likely forms on the nano-titania surface, which in turn contributes to the electrical conduction. The conductivity depended on relative humidity. Using a hydrogen concentration cell, we found that the electromotive force (EMF) of the nano-titania was almost the same as the theoretical value. These results suggest that the main conduction mechanism is proton conduction on the surface of the titania nanoparticles with the aid of sulfonic acid groups bound to the surface of the oxide.
\end{abstract}

Keywords: nano-oxide; proton conductor; acid-modified titania; surface conduction 


\section{Introduction}

Recently, reduction of the burden placed on the environment has been strongly demanded to achieve a sustainable society. One possible approach for accomplishing this is to transition from the existing economy to a hydrogen economy. In this economy, hydrogen is produced by water electrolysis using renewable energy such as solar power, and the hydrogen is then converted into electricity by fuel cells.

Nafion, which is a typical polymer-type proton conductor consisting of a polytetrafluoroethylene (PTFE) backbone and a perfluorinated ether side-chain terminating with sulfonic acid groups, is used as the electrolyte in polymer electrolyte fuel cells (PEFCs). Although Nafion exhibits high conductivity at low temperature, it cannot be used over $100^{\circ} \mathrm{C}$ because of its low stability at high temperature. In addition, problems such as high production costs and crossover of reactant gases during fuel cell operation remain [1]. Accordingly, development of a proton conductor as an alternative to Nafion is highly desirable.

As shown in Fig. 1, we considered that a new proton conductor can be developed by replacing the PTFE of Nafion with an oxide. If the PTFE backbone can be replaced by a low-cost thermally stable oxide, a proton conductor that in turn shares these favorable properties can be realized. From another perspective, this type of proton 
conductor can be classified as "acid-modified oxide" type proton conductor. Kanamura et al. have reported sulfuric acid-modified porous silica [2], and Miyayama et al. have reported a zirconia-based material [3]. In addition to sulfuric acid-modified oxides, phosphoric acid-modified oxides have been investigated by several groups [4-8].

In this paper, we report a novel acid-modified oxide type proton conductor, namely, sulfuric acid-modified "nano-titania", which was synthesized by hydrolysis and precipitation of titanyl sulfate. In this report, we discuss in detail the material's proton conduction properties, such as electrical conductivity and ionic transport number.

\section{Experimental}

\subsection{Sample preparation}

Hydrous sulfated nano-titania was prepared as follows. First, $10 \mathrm{~g}$ of titanyl sulfate ( $\mathrm{TiOSO}_{4} \cdot n \mathrm{H}_{2} \mathrm{O}, n=1 \sim 2$, Kishida Chemical Co., Ltd.) was dissolved into $300 \mathrm{~mL}$ of water and stirred continuously for $40 \mathrm{~min}$. The solution was then heated under continuous stirring, thereby affording a white precipitate at around $70^{\circ} \mathrm{C}$. The white precipitate was collected by suction filtration, washed 5 times with $100-\mathrm{mL}$ portions of distilled water, and dried at room temperature overnight. The resultant dried powder was 
the hydrous sulfated nano-titania.

The amount of sulfate groups in the sample was estimated by acid-base titration. The titration was performed by dispersing the sample powder into water and adding sodium hydrate solution, with phenolphthalein solution as an indicator. In addition, the amount was also discussed from the results of thermal gravimetric analysis (Thermo plus TG8120, Rigaku Corporation). The crystal structure and crystallite size of the sample was determined by X-ray diffractometry (Rint 2500HLR+, Rigaku Corporation). The condition of the sulfate group adsorbed on the nano-titania was observed by diffuse reflectance FT-IR spectroscopy (FT/IR-610, JASCO Corporation) at room temperature.

\subsection{Conductivity and EMF measurements}

The conductivity was measured by the four-terminal AC impedance method. The sample powder was shaped into a bar with a mold, and then pressed at $300 \mathrm{MPa}$ on a cold isostatic press (CIP). The relative density of the bar sample was around $60 \%$. Silver paste, which is conductive without sintering, was applied as electrode to the bar sample. Impedance measurements were performed in the frequency range of $5 \mathrm{~Hz}$ to $1 \mathrm{MHz}$ with applied voltage of $0.1 \mathrm{~V}$ at $30 \sim 350^{\circ} \mathrm{C}$ in a humidified oxygen atmosphere; these measurements were carried out on an impedance analyzer (Model 1260, Solartron 
Analytical).

The ionic (proton) transport number was determined from the electromotive force (EMF) measurement using a hydrogen concentration cell. In order to obtain gas-tight specimens, the sample powder was mixed with PTFE at a ratio of $40 \mathrm{vol} \%$ sample powder to $60 \mathrm{vol} \%$ PTFE, and pressed into a disk at $0.3 \mathrm{MPa}$. The thickness of the disk was about $0.7 \mathrm{~mm}$. Platinum-supported carbon electrodes were attached to both surfaces of the disk. The experimental apparatus shown in Fig. 2 was used to measure EMF, and the hydrogen concentration was set as follows.

$$
x \% \mathrm{H}_{2}-\mathrm{Ar}(x=1,5.1,17.1,100) \mid \text { disk } \mid 1 \% \mathrm{H}_{2}-\mathrm{Ar} .
$$

The EMF was measured at $x \% \mathrm{H}_{2}-\mathrm{Ar}(x=1,5.1,17.1,100)$ vs. $1 \% \mathrm{H}_{2}-\mathrm{Ar}$. The flow rate of each gas was set at $100 \mathrm{~mL} / \mathrm{min}$. In the EMF measurements, sometimes the open-circuit voltage under the $1 \% \mathrm{H}_{2} / 1 \% \mathrm{H}_{2}$ condition deviated from $0 \mathrm{mV}$ (within \pm 0.7 $\mathrm{mV})$; this deviation in voltage was treated as an offset in the EMF measurement.

\section{Results and discussion}

The XRD pattern of the sample powder is shown in Fig. 3: the crystal structure of the material was anatase. It was also found that the XRD peaks were broad since the 
crystallite size of the powder was small. The crystallite diameter estimated from Scherrer's equation was about $10-15 \mathrm{~nm}$.

The amount of sulfate groups in the sample powder was estimated to be about $1.1 \times 10^{-3} \mathrm{~mol} / \mathrm{g}$ from the acid-base titration. Figure 4 shows the thermal gravimetric analysis curve of the sample powder. The weight loss of the sample powder started at two points: $50^{\circ} \mathrm{C}$ and $450^{\circ} \mathrm{C}$. The weight loss at around $450^{\circ} \mathrm{C}$ appeared to be caused by desorption of sulfuric acid. Thus, this result also indicates that the sample powder contained a large amount of sulfate groups. On the other hand, the weigh loss at around $50^{\circ} \mathrm{C}$ appeared to be caused by desorption of water, indicating that a large amount of water was also adsorbed on the sample powder.

The Arrhenius plot of the conductivity of the bar-shape sample is shown in Fig. 5. First, the conductivity was measured as the sample was heated from $30^{\circ} \mathrm{C}$ to $350^{\circ} \mathrm{C}$ (Fig. 5, filled circles); second, the conductivity was measured again as the sample was cooled from $350^{\circ} \mathrm{C}$ to $30^{\circ} \mathrm{C}$ (Fig. 5, open circles). The conductivity at $30^{\circ} \mathrm{C}$ in the heating process was around $10^{-4} \mathrm{~S} \mathrm{~cm}^{-1}$, and decreased with increasing temperature. The conductivity in the cooling process also exhibited a similar trend: the conductivity increased with decreasing temperature. However, the conductivity in the cooling process became higher than that in the heating process overall. It is particularly notable 
that the conductivity at $30^{\circ} \mathrm{C}$ in the cooling process reached $\sim 10^{-2} \mathrm{~S} \mathrm{~cm}^{-1}$, which is two orders of magnitude higher than that in the heating process. This result indicates that the conductivity of the sample powder was increased by heat treatment at $350^{\circ} \mathrm{C}$. To determine the reason of the increase in the conductivity, we measured the change in the diffuse reflectance FT-IR spectra before and after heat treatment at $350^{\circ} \mathrm{C}$ (Fig. 6). After heat treatment, many peaks were observed at around $3500 \mathrm{~cm}^{-1}$, at $1650 \mathrm{~cm}^{-1}$ and at $980 \sim 1250\left(978,1047,1141\right.$ and 1245) $\mathrm{cm}^{-1}$. The peaks at around $3500 \mathrm{~cm}^{-1}$ and 1650 $\mathrm{cm}^{-1}$ correspond to the stretching vibration and bending vibration of water, and were also observed before heat treatment. On the other hand, the peaks at $980 \sim 1250 \mathrm{~cm}^{-1}$ were observed only after the heat treatment, indicating that the chemical species that corresponds to these peaks is the reason for the conductivity increase. Arata et al. have reported that bidentate sulfate coordination on titania exhibits IR spectral peaks at around $980-990,1040,1130-1150$ and $1210-1230 \mathrm{~cm}^{-1}$ [9]. Thus, the conductivity increase was likely due to the formation of bidentate sulfate coordination caused by the heat treatment.

As mentioned above, the conductivity increased with decreasing temperature, indicating that the conductivity possibly increases with relative humidity: relative humidity in Fig. 5 decreases with increasing temperature since $P_{\mathrm{H} 2 \mathrm{O}}$ was fixed at 2.3 
$\mathrm{kPa}$. Therefore, we examined the dependence of conductivity on relative humidity (Fig.

7). The conductivity increased with relative humidity; in particular, the conductivity at relative humidity of $80 \%$ was around $10^{-1} \mathrm{~S} \mathrm{~cm}^{-1}$, three orders of magnitude higher than that at relative humidity of $10 \%$. This result suggests that water adsorption on the surface of the nano-titania particles strongly affects conductivity. The trends shown in Fig. 7 are similar to that of the proton conduction in Nafion. Thus, taking into account the results shown in Figs. 5-7, it is likely that the conductivity of the nano-titania was also caused by proton conduction, similar to the proton conduction in Nafion. We attribute the proton conduction of the nano-titania to the sulfate groups surrounded by water molecules.

An Arrhenius plot of the conductivity when relative humidity was fixed at $80 \%$ was shown in Fig. 8. The conductivity showed about $10^{-1} \mathrm{~S} \mathrm{~cm}^{-1}$ in the temperature range from $100^{\circ} \mathrm{C}$ to $50^{\circ} \mathrm{C}$. We can conclude that the high proton conductivity of the nano-titania can be maintained in wide range of temperature by keeping high relative humidity.

However, the gradient of the Arrhenius plot seems to be negative against reciprocal temperature, although it should be positive in nature. This negative gradient seems to be due to the difficulty in a precise control of relative humidity; we need a 
more precise control of relative humidity in order to obtain the accurate gradient in further investigations.

The EMF of the hydrogen concentration cell in Eq. (1) is plotted against the natural logarithm of hydrogen pressure, $\ln \left(\mathrm{PH}_{2}{ }^{\prime} / \mathrm{PH}_{2}{ }^{\prime}\right)$, in Fig. 9. For comparison, the theoretical value calculated from Nernst equation is also shown as a dash line in Fig. 9. The EMF measured at each temperature agreed well with the theoretical value. The average of the proton transport number $\left(t_{\mathrm{H}^{+}}\right)$estimated from the following eq. (2) was 0.94 for $50^{\circ} \mathrm{C}$ and 0.93 for $30^{\circ} \mathrm{C}$.

$t_{\mathrm{H}^{+}}=\frac{E M F_{\text {obs }}}{E M F_{\text {theo }}}$

Where $E M F_{\text {obs }}$ is a EMF observed and $E M F_{\text {theo }}$ is a theoretical.

This result indicates that the conductivity of the sample powder was originated from proton conduction, not electron conduction. Thus, it can be concluded that nano-titania synthesized by hydrolysis of titanyl sulfate is a highly proton conductive material with $10^{-1} \mathrm{~S} \mathrm{~cm}^{-1}$ at around $50^{\circ} \mathrm{C}$ at a maximum.

\section{Conclusion}

The proton conduction of the hydrous sulfated nano-titania synthesized by hydrolysis of titanyl sulfate was investigated. The crystallite size of the obtained 
nano-titania was around $10-15 \mathrm{~nm}$. It was found that the conductivity of the nano-titania increased after heat treatment at $350^{\circ} \mathrm{C}$, and this conductivity increase was attributed to the formation of bidentate sulfate coordination during heat treatment. The conductivity increased with relative humidity, and had little dependance on temperature. The maximum conductivity obtained was $10^{-1} \mathrm{~S} \mathrm{~cm}^{-1}$ at $50{ }^{\circ} \mathrm{C}$ and relative humidity of $80 \%$. The EMF measurements at $30^{\circ} \mathrm{C}$ and $50^{\circ} \mathrm{C}$ indicated that the conductive species of the nano-titania were protons, and that the proton transport number of the material was almost unity.

Acknowledgements

This study was supported by the Industrial Technology Research Grant Program in $08 \mathrm{C} 46583 \mathrm{c}$ from the New Energy and Industrial Technology Development Organization (NEDO).

References

[1] P. Costamagna and S. Srinivasan, J. Power Sources, 102, (2001) 242. 
[2] S. Hara, M. Miyayama, Solid State Ionics, 168 (2004) 111.

[3] H. Munakata, H. Chiba, K. Kanamura, Solid State Ionics 176 (2005) 2445.

[4] M. Nogami, H. Matsushita, Y. Goto, T. Kasuga, Adv. Mater., 12 (2000) 1370.

[5] G. Li, M. Nogami, Y. Abe, Solid State Ionics 83 (1996) 209.

[6] A. Matsuda, T. Kanazaki, K. Tadanaga, M. Tasumisago, T. Minami, Electrochim. Acta 47 (2001) 815.

[7] A. Matsuda, T. Kanazaki, K. Tadanaga, M. Tsumisago, T. Minami, Solid State Ionics 145 (2001) 161.

[8] T. Tsuru, Y. Yagi, Y. Kinoshita, M. Asada, Solid State Ionics, 158 (2003) 343.

[9] K. Arata, M. Hino, Mat. Chem. Phys. 26 (1990) 213-237. 
Figure captions

Fig. 1 Conceptual diagram of the proton conductor, the "acid-modified nano-oxide".

Fig. 2 Schematic diagram of experimental apparatus for EMF measurement of hydrogen concentration cell.

Fig. 3 XRD pattern of hydrous sulfated nano-titania.

Fig. 4 Thermal gravimetric analysis curve for hydrous sulfated nano-titania.

Fig. 5 Conductivity of hydrous sulfated nano-titania $\left(P_{\mathrm{H} 2 \mathrm{O}}\right.$ fixed at $\left.2.3 \mathrm{kPa}\right)$.

Fig. 6 Diffuse reflectance FT-IR spectra of the hydrous sulfated nano-titania (a) before heat treatment and (b) after heat treatment.

Fig. 7 Dependence of conductivity of hydrous sulfated nano-titania on relative humidity at $100^{\circ} \mathrm{C}$.

Fig. 8 Dependence of conductivity of hydrous sulfated nano-titania on temperature at RH of $80 \%$.

Fig. 9 Observed EMF from hydrogen concentration cell. 


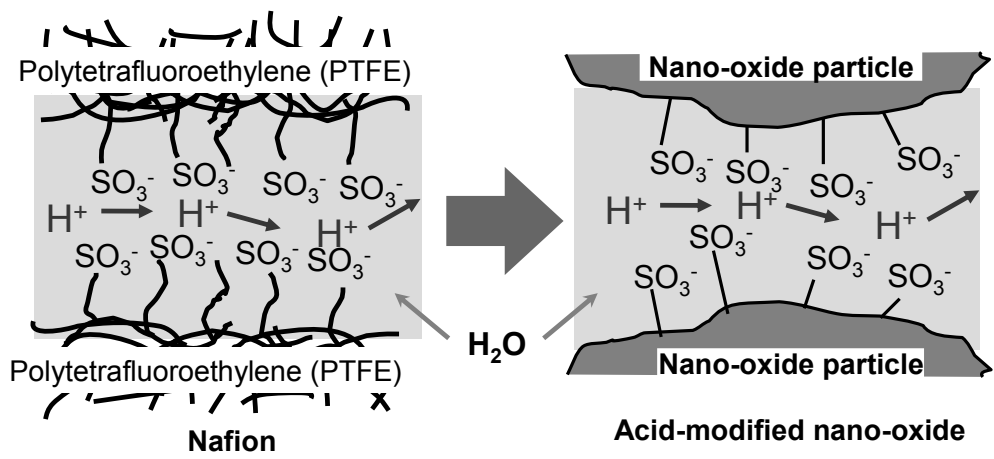

Fig. 1 Conceptual diagram of the proton conductor, the "acid-modified nano-oxide". 


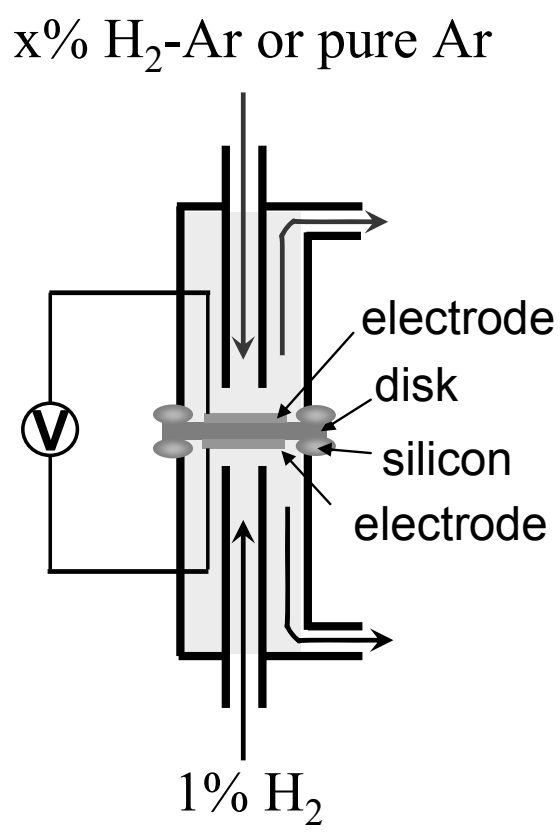

Fig. 2 Schematic diagram of experimental apparatus for EMF measurement of hydrogen concentration cell. 


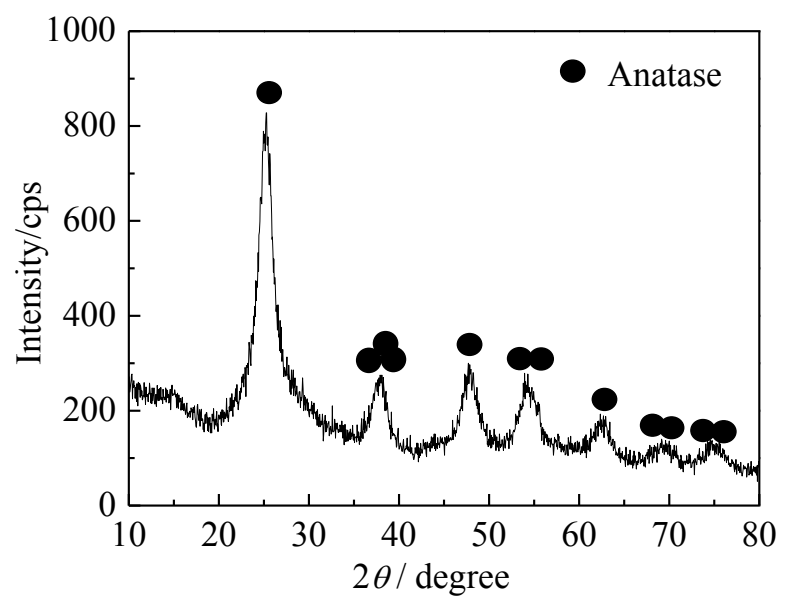

Fig. 3 XRD pattern of hydrous sulfated nano-titania. 


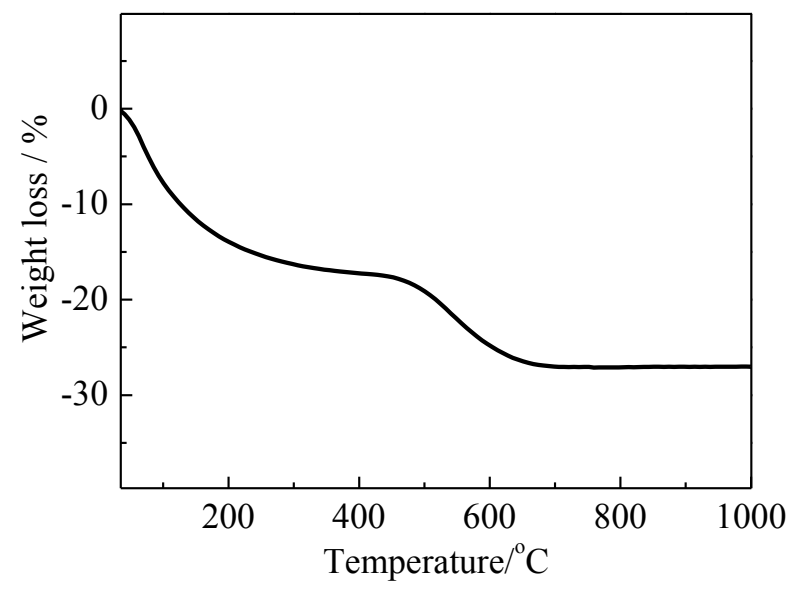

Fig. 4 Thermal gravimetric analysis curve of hydrous sulfated nano-titania. 


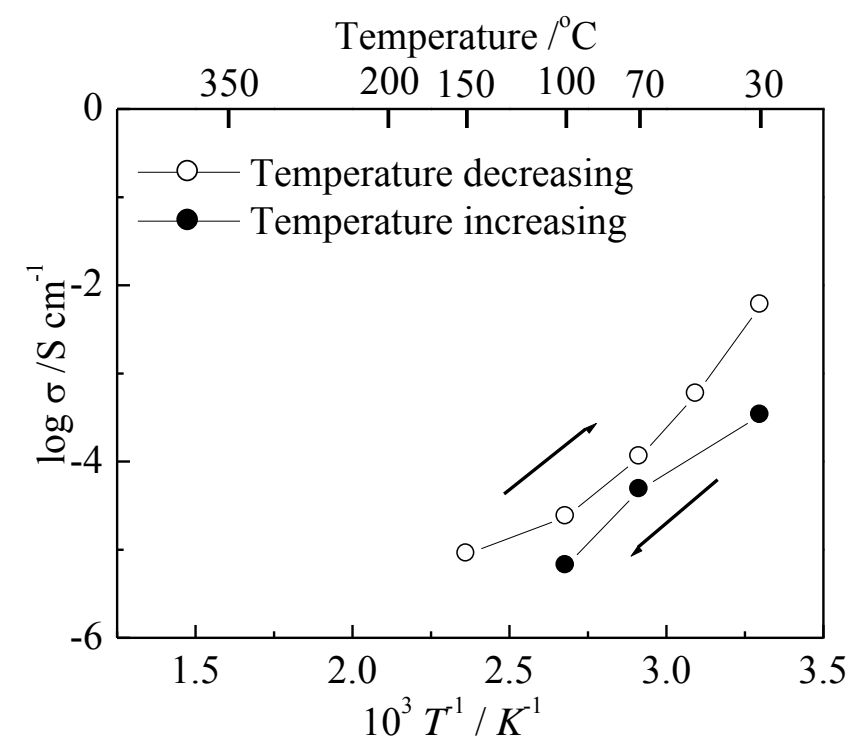

Fig. 5 Conductivity of hydrous sulfated nano-titania $\left(P_{\mathrm{H} 2 \mathrm{O}}\right.$ fixed at $\left.2.3 \mathrm{kPa}\right)$. 


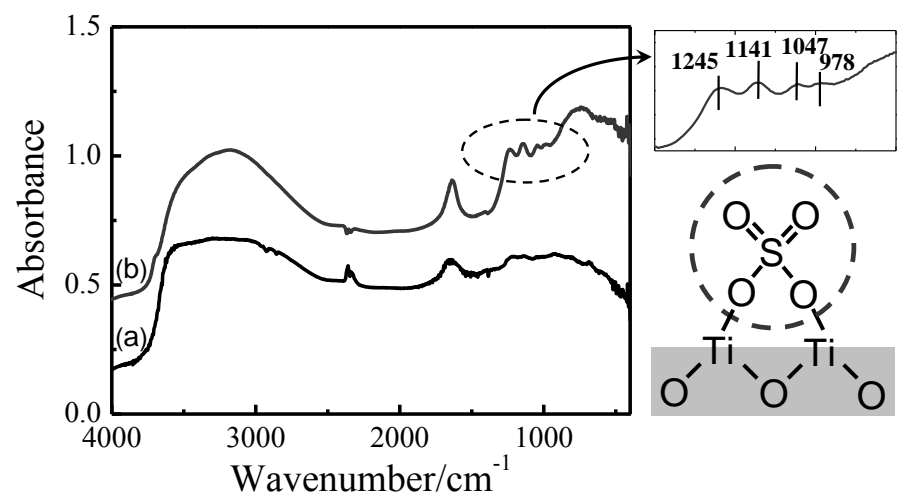

Fig. 6 Diffuse reflectance FT-IR spectra of the hydrous sulfated nano-titania (a) before heat treatment and (b) after heat treatment. 


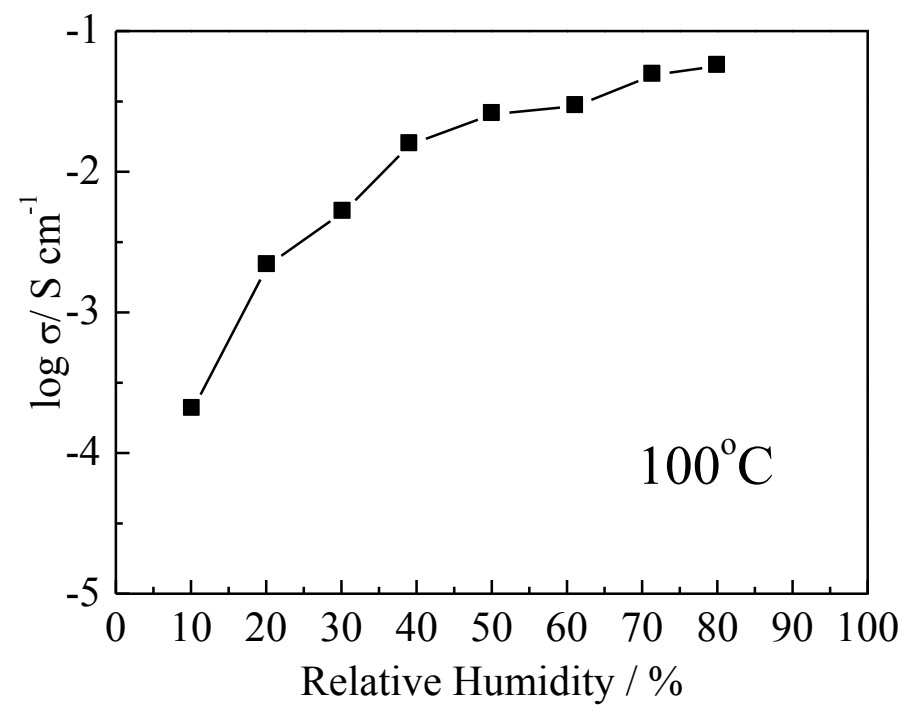

Fig. 7 Dependence of conductivity of hydrous sulfated nano-titania on relative humidity at $100^{\circ} \mathrm{C}$. 


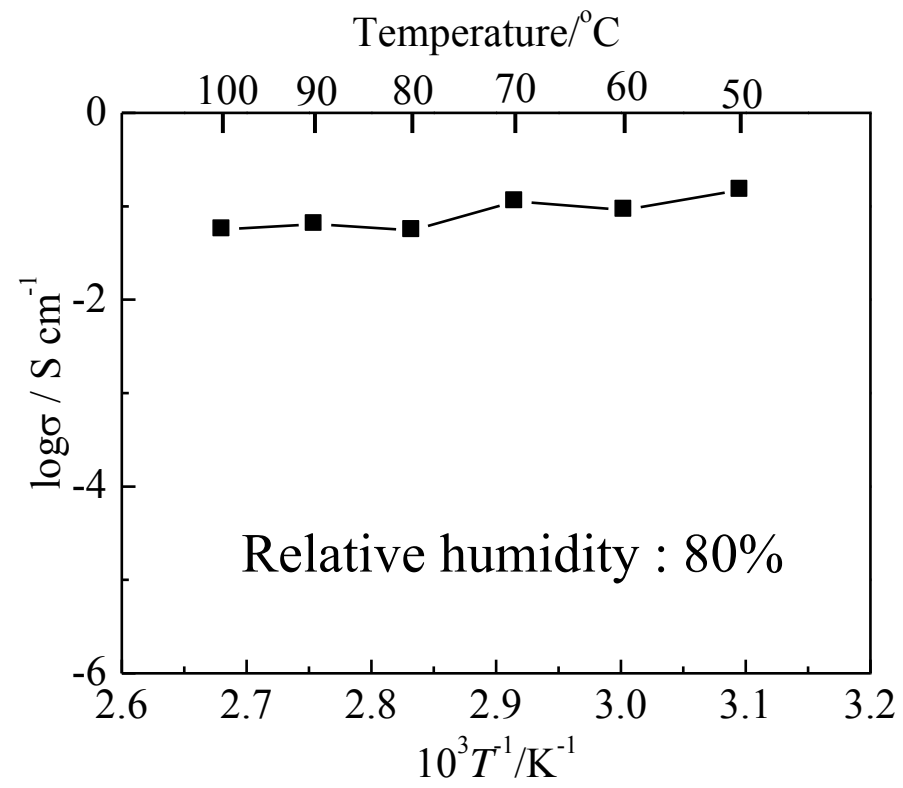

Fig. 8 Dependence of conductivity of hydrous sulfated nano-titania on temperature at RH of $80 \%$. 


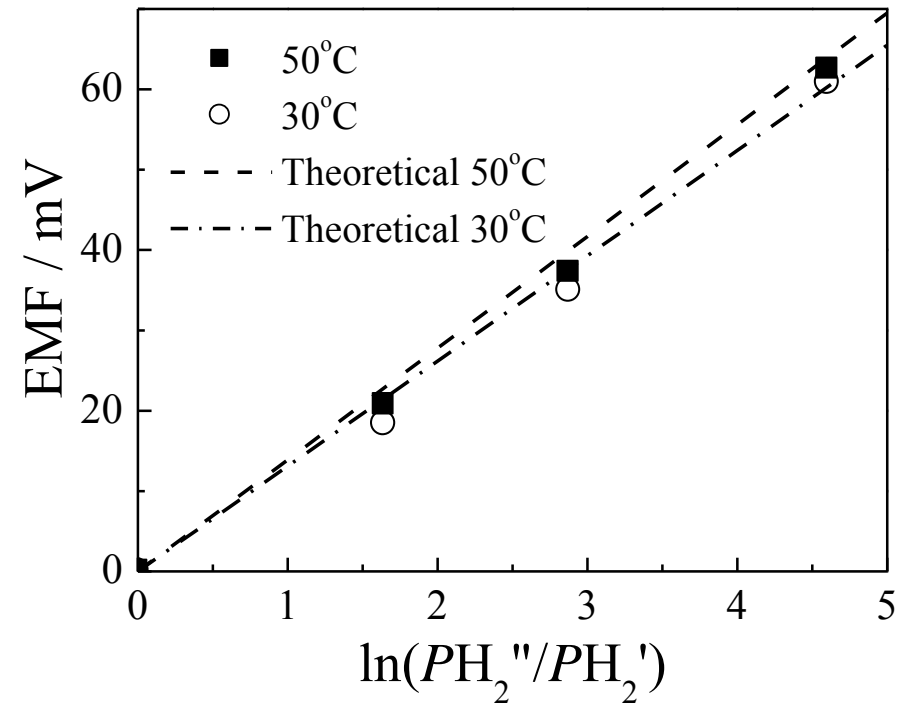

Fig. 9 Observed EMF from hydrogen concentration cell. 